\title{
Recent Advances and Controversies in Pediatric Surgery
}

\author{
Yogesh Kumar Sarin ${ }^{1}$
}

Received: 19 April 2017 / Accepted: 19 April 2017 /Published online: 14 June 2017

(C) Dr. K C Chaudhuri Foundation 2017

Medicine is forever evolving. As we move towards new frontiers and reach out for new advances, we often tread through the controversies and opposing views. The protagonists and antagonists for various forms of management of the medical/ surgical conditions keep on putting forth their arguments in favor of adoption for specific courses of actions. This lack of consensus could be due to lack of in-depth knowledge, institutional limitations, differences in philosophies, societal acceptance or simply because that the medical fraternity has not 'arrived' yet. Putting forth a Symposium on the recent advances and controversies in Pediatric Surgery was long overdue. The fifteen review articles spread out in next three issues will be 'value addition' to the Indian Journal of Pediatrics. The contents are clearly presented and will not only interest surgeons but also medical pediatricians.

The present July issue focuses on the Pediatric Urology issues. It is heartening to know that not only the pediatric surgeons and some urologists, but also the pediatric nephrologists work in tandem to give the best to the children. This issue talks about the all-important entities of ureteropelvic junction obstruction (UPJO), vesico-ureteric reflux (VUR), neurogenic bladder (NB), inguinal hernia and hypospadias. The article on UPJO discusses the present dilemma in treating 'asymptomatic' children diagnosed to have unilateral PUJO as there seems to be hardly any consensus about the cut-off values on the imaging and radio-imaging parameters. New urinary biomarkers are being explored [1]. The article on VUR dwells upon the controversy of using continuous

Yogesh Kumar Sarin

yksarin@ hotmail.com

1 Department of Pediatric Surgery, Maulana Azad Medical College and Lok Nayak Hospital, New Delhi 110002, India antibiotic prophylaxis in Grade I and II VUR and clearly brings out the indications where surgical intervention is required [2]. The next article provides a comprehensive summary of the clinical approach, investigative modalities and management of a child with neurogenic bladder disease due to myelodysplasia [3]. The fourth article on inguinal hernia brings some meeting point of open and laparoscopic approach in the management of inguinal hernia; this is traditionally an entity where very strong opposing stands have been taken by different pediatric surgeons [4]. The article on hypospadias focuses on recent advances as regards the hormonal treatment, genetics and bioengineering [5].

The second 'August' issue is a mixed bag. There is a retrospective institutional review on the management of vascular anomalies treated with steroids, $\beta$-blockers and intralesional sclerotherapy using sodium tetradecyl sulfate and surgery [6]. The article on Hirschsprung's disease details the systemic approach to its diagnosis [7]. There is an article mentioning the merits of endoscopic third ventriculostomy for hydrocephalus; this technology is expected to replace the ventriculo-peritoneal shunt surgery in not-too-far future [8]. There is one more article that deals with surgical neonates; the paradigm shift and the ensuing ethical issues in the mangement of neonates with congenital diagphragmatic hernia are discussed [9]. The issue also deals with the controversy of single $v s$. multiple staged surgical management of ano-rectal malformations [10].

The third 'September' issue is all about pediatric hepatology and pediatric urology. There is an article about the relevance of HIDA scan and preoperative liver biopsy for exclusion of biliary atresia in neonatal cholestasis syndrome [11]. Then we explore whether medical (endoscopic management) or surgical treatment is the mainstay of management of extrahepatic portal venous obstruction, a very tight rope to tread on, as we witness turf wars between many sister-subspecialties [12]. Then we have philosophical discourse on extremely controversial issue 
of gender reassignment in 'inadequate' male children (aphallia, cloacal exstrophy, micropenis) [13]. This is followed by an article that talks about convergence of two divergent philosophies of management of Wilms' tumor- upfront surgery (Children's Oncology Group) and upfront chemotherapy (Société Internationale d'Oncologie Pédiatrique). The authors also describe the merits of doing pre-chemotherapy trucut biopsy through retroperitoneal route of Wilms' tumor as advocated by United Kingdom Children's Cancer Study Group [14]. Last but not the least, there is an article that supports the use of rectal bladder for the underprivileged children born with the exstrophy bladder in light of the poor outcomes with reconstructive techniques and describes a technique that has not been described in literature hitherto- Yogesh's cystorectostomy [15].

It is believed that the Symposium would help clearing some pre-existing doubts and the readers would be forced to reappraise their own management of each. For some others, it would provide some evidence reinforcing their preconceived ideas of these conditions.

\section{Compliance with Ethical Standards}

Conflict of Interest None.

Source of Funding None.

\section{References}

1. Sarin YK. Is it always necessary to treat an asymptomatic hydronephrosis due to ureteropelvic junction obstruction? Indian J Pediatr. 2017; doi:10.1007/s12098-017-2346-9.
2. Babu R, Chowdhary S. Controversies regarding management of vesico-ureteric reflux. Indian J Pediatr. 2017; doi: 10.1007/ s12098-017-2359-4.

3. Sripathi V, Mitra A. Management of neurogenic bladder. Indian J Pediatr. 2017; doi: 10.1007/s12098-017-2356-7.

4. Raveenthiran V, Agarwal P. Choice of repairing inguinal hernia in children: open versus laparoscopy. Indian J Pediatr. 2017; doi: 10. 1007/s12098-017-2354-9.

5. Mitra A, Sarin YK. Use of hormones, tissue factors and bioengineering in management of hypospadias. Indian J Pediatr. 2017; doi: 10.1007/s12098-017-2347-8.

6. Gupta A, Verma A, Dhua A, Bhatnagar V. Vascular anomalies: a pediatric surgeon's perspective. Indian J Pediatr. 2017; doi: 10. 1007/s12098-017-2355-8.

7. Das K, Mohanty S. Hirschsprung disease - current diagnosis and management. Indian J Pediatr. 2017; doi: 10.1007/s12098-0172371-8.

8. Kumar V, Bodeliwala S, Singh D. Controversy about management of hydrocephalus - shunt vs. endoscopic third ventriculostomy. Indian J Pediatr. 2017; doi: 10.1007/s12098-017-2338-9.

9. Bhatnagar SN, Sarin YK. Management of congenital diaphragmatic hernia in newborn - paradigm shift and ethical issues. Indian $\mathrm{J}$ Pediatr. 2017; doi: 10.1007/s12098-017-2374-5.

10. Gangopadhyay AN, Pandey V. Controversy of single versus staged management of anorectal malformations. Indian J Pediatr. 2017; doi: 10.1007/s12098-017-2373-6.

11. Mandelia A, Lal R, Mutt N. Role of hepatobiliary scintigraphy and preoperative liver biopsy for exclusion of biliary atresia in neonatal cholestasis syndrome. Indian J Pediatr. 2017; In Press.

12. Lal R, Sarma MS, Gupta MK. Extrahepatic portal venous obstruction: what should be the mainstay of treatment? Indian J Pediatr. 2017; doi:10.1007/s12098-017-2390-5.

13. Raveenthiran V. Controversies of sex re-assignment in genetic males with congenital inadequacy of the penis. Indian J Pediatr. 2017; In Press.

14. Kumar A, Bakhshi S, Agarwala S. Is pre-operative chemotherapy desirable in all patients of Wilms' tumor? Indian J Pediatr. 2017; In Press.

15. Sarin YK, Sekhon V. Exstrophy bladder - reconstruction or diversion for the underprivileged. Indian J Pediatr. 2017; In Press. 